Miscellanea Anthropologica et Sociologica 2019, 20(1): 36-45

Tomasz Kąkol ${ }^{1}$

\title{
On Empathy. E. Stein and R. Ingarden vs. Cognitive Psychology
}

In this paper I compare (using as paradigmatic examples E. Stein and R. Ingarden) phenomenological theories of empathy (understood as "mind-reading") with contemporary cognitivists' approach to this issue, arguing that although they are prima facie incompatible, in fact they can be seen as complementary. Since empathy is indispensable in practice, a correct conceptualization of this topic is desirable.

Key words: cognitive science(s), empathy, R. Ingarden, mind-body problem, mind-reading, phenomenology, E. Stein

'Empathy' in the phenomenological sense (German 'Einfuehlung') has a broader meaning than it does in contemporary psychology, as it refers to knowing other mind(s). Cognitive science uses the suggestive term 'mind-reading' here. At first glance the accounts of empathy given by such classic phenomenologists as Stein and Ingarden seem to be in tension with contemporary cognitive theories, particularly because those two philosophers seem to maintain that empathy is a kind of direct or immediate cognition - or simply another kind of perception. Cognitivists, in turn, purport to deny this, holding that empathy is somehow mediated - in short, that it is a kind of inference or reasoning. But upon closer examination this contrast vanishes, as I try to show in what follows. Let's start with Edith Stein's doctoral thesis on empathy.

1. At the beginning of her work Stein states that "there is a close, yet very loose [emphasis added] parallel between" empathy and other perception such as sensory perception of a mesoscopic physical object (Stein 1989: 6-7). The reason is

1 University of Gdańsk, Faculty of Social Sciences, Institute of Philosophy, Sociology and Journalism, Gdańsk (Poland); tomasz.kakol@ug.edu.pl. 
that the content of an act of empathy - the mental state of the other - is not primordially (originaer) given even in the primordial act of empathy, similarly as the averted sides of this table are not primordially given in my actual primordial act of perception of this table. 'Being loose' of this parallel means that those averted sides in virtue of the essence of this act can always be given primordially, whereas this is not the case with empathy. Nevertheless, Stein holds that empathy is a kind of a sui generis perception (Erfahrung). That is why she criticizes three genetic theories of empathy (imitation theory, association theory, and analogy theory). For their consequence, as Stein thinks, is that empathy is not a kind of Erfahrung. It is crucial to note here that Stein doesn't see genetic psychology (to use the term from the beginning of the $20^{\text {th }}$ century) as a rival in respect to phenomenology: on the contrary, she precisely formulated questions pertaining to this science: "(1) What psychological mechanism functions in the experience (Erlebnis) of empathy? (2) How has the individual acquired this mechanism in the course of his development?" (Stein 1989: 123, footnote 31). Still, what Stein opposes is having consequences inconsistent with the phenomenological description of the phenomenon. First, the imitation theory of Adam Smith is recalled - Stein writes: "If, as in memory, we put ourselves in the place of the foreign 'I' and suppress it while we surround ourselves with its situation, we have one of these situations of 'appropriate' experience (Erlebnis). If we then again concede to the foreign 'I' its place and ascribe this experience to him, we gain a knowledge of his experience" (Stein 1989: 14). Interestingly, what Stein calls the imitation theory is, to be precise, a conception by Theodor Lipps, though interpreted rather as a theory according to which empathy is a kind of contagion of feeling. ${ }^{2}$

But later the situation becomes blurred: Stein talks about "emphatic representation" (Stein 1989: 57, 115), contradicting her made earlier claim that empathy is not a representational act (Stein 1989: 19). Furthermore, she begins to speak of empathy as an "interpretation" and "projecting into" (hineinversetzen, (Stein 1989: 61ff), that is, interpreting the other particular body as a living one and of "transferring the self into the other's orientation" (Stein 1989: 65). Indeed, the following passage is very similar to Smith's account, formerly rejected: "Understanding of a bodily expression is based on comprehending the foreign living body already interpreted as a living body of an 'I'. I project myself into the foreign living body, carry out the experience already co-given to me as empty

\footnotetext{
2 Stein also invokes here Max Scheler's four arguments against the imitation theory: 1) imitation presupposes empathy ("presupposes a comprehending expression as expression"); 2) "we also understand expressions that we cannot imitate, for example the expressive movements of animals"; 3) "we comprehend the inadequacy of an expression, an impossibility if the comprehension occurred by an imitation of the expression alone"; 4) "we also understand experiences unfamiliar to us from our own earlier experience" (Stein 1989: 123, footnote 32). Later we will see how to respond to them.
} 
[emphasis added] with its countenance, and experience the experience ending in this expression" (Stein 1989: 82).

2. Ingarden in his The Controversy over the Existence of the World draws an analogy between the physical object contrasted with its adumbrations (in which it is bodily given in perception) and the state of one's soul (even from the first person perspective!) contrasted with its bodily expressions (wyrazy). But he softens the "immediate" character of empathy by adding that psychic facts are "in some sense" (niejako) perceived in bodily expressions (Ingarden 1987a: 224). His hesitation regarding this issue is further visible in that, on the one hand, it seems impossible, as Ingarden suggests, for at least certain bodily expressions not to be immediately grounded by appropriate mental facts (Ingarden explicitly mentions here as examples dissatisfaction and astonishment, accompanied by particular facial expressions - (Ingarden 1987a: 224). But on the other hand, there are also, he continues, mental facts that may not be bodily expressed, or expressed "imperfectly", as he writes, or inadequately, due to e.g., pretending.

One can try of course to interpret this in a way charitable to Ingarden: both dissatisfaction and astonishment can be feigned, so it is a matter of an inappropriate example, not hesitation. But the problem is deeper: for even if mental states are given in bodily expressions through empathy in some similar way as ordinary objects are given in adumbrations through perception, Husserl and both of his pupils know that this is possible by the essence of the act of such a perception that those intended objects are illusory. Consequently, the same goes for "other minds", and if we stress, following Ingarden, that this applies equally to our own self, the question arises: what is the epistemological difference between introspection, empathy, and outer perception?

Here, I think, it is necessary to look closer at Ingarden's theory of mind (taken over, with several changes, from Husserl, and partly shared with Stein).

1) We should distinguish between I or the subject, the stream of consciousness, the soul, our body as felt from the first person perspective (let us call it 'Leib'), and our body (let us call it 'Körper') as perceived from "the outside" (that does not mean necessarily "by others").

2) The stream of consciousness has the form of a process; its contents are experiences.

3) I or the subject endures through time and is indispensable for the unity of the stream of consciousness (continuity and connectedness of experiences does not suffice for that unity). It is absolutely indivisible (Ingarden 1987: 116), unextended (Ingarden 1987a: 211) and immaterial (Ingarden 1987: 140) as well. The reason is simply that the question about its localization is meaningless (Ingarden 1987a: 213) (compare below, point 5). 
4) The soul, which also endures through time, is the locus (not in the spatial sense of the term) of psychological "powers" (and "weaknesses"), or, more precisely, mental dispositions and character traits.

5) 'I' has several meanings. It can denote a pure subject of consciousness ('I' taken only as a subject of experience, or as an agent of conscious actions) or a particularly structured center of the soul; it can also denote a person and, finally, a psychophysical individual such as a human being.

6) Person is a soul with a structured center - I.

7) Leib and Körper are one and the same, albeit experienced in two ways (Ingarden 1987a: 194-195, 209; however, compare pp. 213f, footnote 86).

8) Leib is the (phenomenal) locus of the kinesthetic, proprioceptive etc. impressions or sensations.

9) The soul and Leib are not identical; the positive characterization of the relation between them is a serious problem for Ingarden - he analyzes several possibilities in terms of his relations of existential (in)separability, (in)dependence and originality/derivativeness, but does not take any definite stand on these matters. It seems that Ingarden's thesis 9) would not be satisfactorily warranted for many people, since it is just the result of the phenomenological insight (according to the author of The Controversy..., we never, phenomenologically speaking, identify ourselves with our body). Maybe we could say instead that Leib has the properties that the soul lacks or/and vice versa: observe that Leib is defined as having several categorical qualities, whereas the soul is the bearer of distinctive dispositions. On the other hand, one could insist that one cannot exclude the possibility that these are the same: that is, there are several dispositional qualities (the power of moving our body, for instance) that have appropriate manifestations (kinesthetic self-experiences in this case). Moreover, it seems that Ingarden's thesis 7) should be revised for similar reasons.

Instead, I propose the following, in my opinion more correct account:

I can think of myself as having no body, just as Descartes, among other people, could. Interestingly, Descartes could do so in a time that was deprived of electronic communication and virtual reality. With a greater effort I can also think of the existence of my physical duplicate lacking my actual conscious mental sphere. If ' $a$ ' and ' $b$ ' are the names of one and the same thing, it cannot be thought of ' $a$ ' without ' $b$ ' (and ' $b$ ' without ' $a$ '), for we speak of one and the same thing, and nothing can exist without itself. Therefore, the popular 'psychophysical identity thesis' is once again false. But it also follows that two weaker theses are dubious (i.e., that purely mental objects are impossible and that an appropriately arranged brain by this sole fact entails the existence of a conscious mind). This argument (favored by Descartes and popularized by Kripke) prima facie suffers from the following defect: it can be thought that water is not $\mathrm{H}_{2} \mathrm{O}$ - and indeed, people thought this 
way in the past. But today we do know that water is $\mathrm{H}_{2} \mathrm{O}$. On the other hand, we don't know whether the psychophysical identity thesis is true. Hence, it is not false, but at most dubious.

The rejoinder is that if the abovementioned thesis is dubious, why should it be certain that purely mental objects are impossible? - or that an appropriately arranged brain necessarily implies a conscious mind? Furthermore, it was Kripke who objected to the alleged analogy between the psychophysical identity thesis and water-like identities. Consider the thesis that light $=$ a beam of photons. When I say "light" in similar contexts I refer to "something we have in this room", as Kripke noted. But this thing is identified by particular sensations it causes in us. Nevertheless, in the case of conscious mental states such as pain, we don't identify this state by particular sensations it causes in us - rather, pain is (identical with) such a sensation.

The next step is to strengthen this minimal dualism (the denial of the psychophysical identity thesis) so as to arrive at a dualism with a causally effective conscious mind, i.e., one able to act freely. In turn, free will cannot be consistently denied for two reasons. First, if someone argues against free will, she must assume that to speak of "the arguments" is inappropriate - rather, one could talk about "forcing" or "brainwashing". Second, even the most extreme "immoralist" assumes that at least one moral norm holds (say, "maximize only your own wellbeing"). But if the norm holds, the very notion of moral obligation presupposes that I can follow that norm and that I can refrain from following it, as Kant rightly observed. And since the problem of human free will is analogous to the problem of the Prime Mover (this was also stressed by Kant ${ }^{4}$ ), the existence of free will is incompatible with the statement that an appropriate physical organization of the brain (or maybe the whole body) necessarily entails the existence of the conscious mind with that particular content.

A critic could say that this is not necessary, for the weaker dualism (i.e., property dualism) is sufficient. ${ }^{5}$ To respond, it suffices to notice that it is not the case that properties are causes - what causes something is the subject of properties instead.

One can point out here that in this way we create "an unbridgeable dualism between lived body and perceived body" (Zahavi 2001: 162), even if not an oldfashioned mind-body dualism. The problem seems to be, as Zahavi puts it, how we then "should ever be able to recognize other embodied subjects" (Zahavi 2001: 162 ) and the objective world in general (Zahavi 2001: 159-160)? Stein perfectly knows and accepts Husserl's view that it is precisely by means of empathy that

A. Cygański takes this argument to be "cheap", as he puts it. See, however, (Chmielecki 2013: 178).

And also Stein. See (Stein 1989: 56, 72).

K. Cekiera's remark. 
we can come to consider our own "zero point of orientation" as a "spatial point among many" (Stein 1989: 63) and in this way we constitute ourselves as a psycho-physical individual. The recognition is thus taken for granted and serves as a motivation for taking ourselves as an unbroken, unified entity. If one wants to go back to the level of her own body, i.e., to explain the recognition of others as made possible only by the empathy directed toward her own body, so to speak (Zahavi 2001: 161, 163), then we only change the place of encountering difficulty: we can, e.g., postulate the existence of a self-representation of her own body which purportedly permits her "to bridge the gap between interiority and exteriority" (Zahavi 2001: 164). And, of course, one has to be warned that if we agree that "thus empathy as the basis of intersubjective experience becomes the condition of possible knowledge of the existing outer world, as Husserl and Royce present it" (Stein 1989: 64), how to avoid petitio principii or regressus, given the fact that this very body (along with its self-representation) is posited?

3. Before passing on to cognitive psychology, let me describe two reasons for my reservations concerning phenomenology conceived as a meaning- and groundbestowing science for everything else (thus was it thought of, albeit to a lesser degree, not only by Husserl, but also by Stein and Ingarden).

Sciences such as physics, chemistry, and biology strive to talk about the world existing independently with regard to us, and it is reasonable to agree that much of what they say is true in the classic sense of the term (or at least sufficiently similar to being true). Everyday knowledge (hence, pre-scientific) is also full of true propositions such as that now I am writing this article and not playing, say, World of Tanks - let alone that I am not a brain in a vat. Philosophers who reject such realism place themselves above the natural sciences and I have no doubts about who is more competent here. The reasonableness of such scientific realism is warranted mostly by the unexplainable otherwise, the celebrated correspondence between older and newer theories (see e.g. Heller 2012). Indeed, the value of epistemology is ambivalent: I agree with T. Sider and other "Australian ontologists" that, on the one hand, "it may well be that the epistemological foundations of speculative metaphysics [=ontology - T.K.] are particularly difficult to secure". But on the other hand, "any theory that rules out the possibility of high-level philosophical knowledge of the world is just another theory" (Sider 2001: xv). After all, there is a recurring problem with epistemological principles such as the Kantian principle of "possible (sensous) experience" or the neopositivist principle of empirical meaning: either they are rejected on their own terms or they generate epistemic regress (see Leszczyński 2014: 169). ${ }^{6}$

\footnotetext{
6 R. Urbaniak recently tried to defend the neopositivist principle (see Urbaniak 2016: 112-115). He neglects regress and considers several positions with regard to the status of the principle stating that "meaningful propositions are either analytic (analytically false or analytically true) or they
} 
Nevertheless, I believe, as I said at the beginning, that both Stein's, Ingarden's, and cognitivists' accounts of empathy can be seen as complementary rather than as rivals. Indeed, what Stein and others called 'genetic psychology', can nowadays be identified with cognitive psychology. As usual in science, this is by no means the last word, but it is instructive to recall theses or rather hypotheses of the latter: 1) Cognitive psychologists agree with phenomenology that there are several grades of empathy (once again, in the broad, phenomenological sense), both in the developmental (or genetic) and structural aspect;

2) Moreover, they agree that it has a quasi-perceptual nature in that, on the one hand, it occurs immediately and its object is experienced as given, not inferred or concluded; on the other, however, this doesn't preclude the underlying unconscious and automatic processes which are similar to reasoning or inference;

3) Lastly, cognitive psychologists argue for the innate or genetic, not environmental or created by socialization source of those faculties and for the existence of the specific parts of the brain engaged in executing those functions, though this is an issue on which phenomenology of course cannot take a stand.

As for the first point, psychologists have studied such faculties as the ability to detect biological (as opposed to mechanical) movement (to be sure, the division has its grey area, since, e.g., Brown's movements have many characteristics attributable to biological ones), the abilities to detect face in general and that particular face (it has been proved that one can have the former without the latter - I mean here the syndrome called prosopagnosia), the ability to detect simple or basic emotions such as fear, astonishment, anger, and happiness (interestingly, it is independent of recognizing faces) and many others. Next come such faculties as attribution of propositional attitudes (that is, mental states whose contents are expressible in the form of a proposition) such as beliefs and desires or pretending (or tactical deception - it is believed to be present among chimps - here the term 'mind-writing' instead of the standard 'mind-reading' will be more appropriate).

satisfy a certain (depending on the appropriate version of the theory) condition of empirical meaningfulness" (p. 112). But below he blatantly states that the option according to which this principle is, as he puts it, an "empirical hypothesis", is not "ruled out" (p. 114). Second, he thinks that it would also be right to treat this criterion as "meaningless" (!), (p. 114) for "many things meaningless from the cognitive point of view are utile, such as making sandwiches" (p. 114). The question is, then, what is the neopositivist principle for? The answer is hilarious: to deny, inter alia, Islam (!), (see very meaningful allusions on p. 124). As for Husserl's principle, W. Płotka states that the supposed dilemma (either contradiction or regress) is false since it falsely excludes the descriptive character of phenomenology (as opposed to argumentative) (Płotka 2015: 40-85). But then the rejoinder suffers from ignoratio elenchi: for we need the criterion of the aptness of descriptions. If, once again following Husserl, one opts for the evidence (understood as in the statement 'It's evident!'), Płotka clearly points out that the evidence is problematic too (Płotka 2015: 83) not only because for phenomenology everything is such (as opposed to being naïve, not reflected upon) but also because the evidence has various "degrees and levels" (p. 262) and is always "horizontal and situated" (p. 272). 
Lastly, several psychologists point out that more complex acts can also exist, ones comprised of both reflexive and reflective (conscious, that is) layers.

As for the mechanism, cognitivists basically take into account two theories: the so-called theory-theory and simulation theory, the latter being the modern descendant of the imitation theory. Both of them have their proponents, but the simulation theory seems to be better warranted after the relatively new discovery of the so-called mirror neurons.

With regard to the second point, it is worth noticing that in this way we can answer Scheler's objections to imitation theory that we cited after Stein. Interestingly, D. Zahavi adds the following charges: 1 . If terms such as 'reasoning' or 'inference' are used to denote "sub-personal processes", then their meanings become unclear; 2. If we claim that we just experience other minds, "the explanatory power" of the alleged sub-personal level processes cannot be "unaffected" - this power, to be sure, becomes weak (Zahavi 2009: 303-304). As for the first one, I see nothing problematic in the notion of automatic or unconscious reasoning, similarly as Zahavi himself sees nothing unusual in that perception of mesoscopic objects such as a stethoscope is not theory-laden in the same sense as "the positing of black holes" is, although it is "influenced by what is co-given with it" (Zahavi 2009: 301). Moreover, I suspect that Stein and Ingarden's hesitation as regards the status of empathy (perception or not?), far from being neglect, reveals that the difference between experience and inference (sometimes) is hard to detect: If I see that the car has run out of gas, then only after reflection can I come to suspect that I performed such reasoning as 'I can see the gas gauge is low; if this is so, then the car has run out of gas; therefore: the car has run out of gas' (or even more complicated: 'I can see that the needle of the gas gouge points to the letter ' $E$ ', that means, 'Empty', so...' etc.). Nevertheless, I would insist that I perceive the lack of gas (although this experience is not infallible) or at least perceive (sub-consciously?) several "empirical facts" along with the perception that this reasoning holds (or at least is sufficiently reliable). In this way I would also answer the second objection.

The question of genesis and neural modules being the base for those abilities is carefully examined. In 2008 it was claimed that experimental study confirmed that newborns are capable of discerning biological movement (Simion, Regolin, Bulf 2008). One of the first signals of the possibility of autism (or "mind-blindness" - in fact, a serious distortion or even the lack of empathy in the phenomenological sense) is that of little interest in faces during the first year. In 2005 it was discovered that even 15-month-old infants (probably unconsciously) discern false beliefs (it had hitherto been believed that only 3-year-olds and older can do this) (Baillargeon, Onishi 2005). The detector(s) of simple or basic emotions is (are) known to be innate; secondary emotions, such as pride, envy, or shame, can also be at least in part based genetically (for example, two-year-old children 
experience shame). In 1999 it was confirmed, using over 100 3-year-old twins (both monozygotic and dizygotic ones) that "two-thirds of children's variance on mind-reading tests is attributable to genetic factors" (Botterill, Carruthers 1999: 94). Moreover, the existence of Williams syndrome suggests that mind-reading or empathy is a distinctive faculty in that people with this syndrome have poor intelligence apart from their prowess at mind-reading (Botterill, Carruthers 1999: 99).

With regard to the identification of specific brain structures purportedly "realizing", to use the term popular in those circles, the cognitive functions I mentioned, the basic methodology is mostly "lesion studies" and/or subtractional neuroimaging by four techniques (fMRI, PET, EEG, MEG), i.e., comparing brain activation measured in control conditions with brain activation measured in experimental conditions. For example, by the famous lesion study in the 90-ies, the famous neurocognitivist Antonio Damasio discovered the key role of the amygdala in the detection and expression of fear (Damasio 2000: 71-76). Both of those methodologies are sometimes used to reject the antinaturalistic theory of mind, but this is, to reassure a phenomenological audience, an obvious non sequitur.

ACKNOWLEDGEMENTS. I would like to thank two anonymous referees who helped me to re-consider the matter more carefully. However, the sole responsibility for errors is mine.

Bibliography

Baillargeon R., Onishi K., 2005, Do 15-month-old-infants understand false beliefs?, Science, no. 308 , pp. 255-258.

Botterill G., Carruthers P., 1999, The Philosophy of Psychology, Cambridge: Cambridge University Press.

Chmielecki A., 2013, Podstawy psychoniki. Ku alternatywie dla cognitive science [The foundations of psychonics. Towards the alternative to cognitive science], Warszawa: Instytut Filozofii i Socjologii Polskiej Akademii Nauk.

Damasio A., 2000, Tajemnica świadomości [original title: The Feeling of what happens], transl. M. Karpiński, Poznań: Rebis.

Heller M., 2012, Spór o realizm strukturalistyczny [The controversy over structural realism] [in:] M. Heller, Filozofia i wszechświat [Philosophy and the universe], Kraków: Universitas.

Ingarden R., 1987, Spór o istnienie świata [The controversy over the existence of the world], vol. 2, part 1, Warszawa: Państwowe Wydawnictwo Naukowe.

Ingarden R., 1987a, Spór o istnienie świata [The controversy over the existence of the world], vol. 2, part 2, Warszawa: Państwowe Wydawnictwo Naukowe.

Leszczyński D., 2014, Fenomenologia, naturalizm i nauka [Phenomenology, naturalism and science] [in:] W. Płotka (ed.), Wprowadzenie do fenomenologii. Interpretacje, 
zastosowania, problemy [Introduction to phenomenology: interpretations, applications, problems], vol. 1, Warszawa: Instytut Filozofii i Socjologii Polskiej Akademii Nauk.

Płotka W., 2015, Studia z fenomenologii poznania. Transcendentalna filozofia Edmunda Husserla a problem wiedzy [Studies in the Phenomenology of Cognition. Transcendental Philosophy of Edmund Husserl and the Problem of Knowledge], Gdańsk: Wydawnictwo Uniwersytetu Gdańskiego.

Sider T., 2001, Four-dimensionalism. An ontology of persistence and time, Oxford: Clarendon Press.

Simion F., Regolin L., Bulf H., 2008, A predisposition for biological motion in the newborn baby, Proceedings of the National Academy of Sciences of the USA, no. 105, pp. 809-813.

Stein E., 1989, On the problem of empathy, transl. W. Stein, Washington, D.C.: Institute of Carmelite Studies Publications.

Urbaniak R., 2016, Lekko nieodpowiedzialne i stronnicze wprowadzenie do filozofii analitycznej [A slightly irresponsible and biased introduction to analytical philosophy], Lublin: Academicon.

Zahavi D., 2001, Beyond Empathy. Phenomenological Approaches to Intersubjectivity, Journal of Consciousness Studies, vol. 8, no. 5-7, pp. 151-167.

Zahavi D., 2010, Empathy, Embodiment and Interpersonal Understanding: From Lipps to Schutz, Inquiry, vol. 53, no. 3, pp. 285-306. 